\title{
Religious and Secular Coping Strategies and Mortality Risk among Older Adults
}

\author{
Lindsey McDougle, PhD \\ Assistant Professor \\ School of Public Affairs and Administration \\ Rutgers University - Newark \\ Sara Konrath, PhD \\ Assistant Professor \\ Lily School of Philanthropy \\ Indiana University \\ Marlene Walk, MSW \\ PhD Candidate \\ School of Social Policy \& Practice \\ University of Pennsylvania \\ Femida Handy, PhD \\ Professor \\ School of Social Policy \& Practice \\ University of Pennsylvania
}

\begin{abstract}
Using data from the Wisconsin Longitudinal Study (WLS), the purpose of this study is two-fold. First, the study is intended to identify coping strategies used by older adults. Second, the study is intended to examine the impact of older adults' chosen coping strategies on mortality reduction. The study focuses specifically on differences in religious and secular coping strategies used by older adults. The findings suggest that although coping strategies differ between those who selfclassify as religious and those who self-classify as non-religious, for both groups social approaches to coping (e.g., attending church and volunteering) were more likely than individual approaches (e.g., praying or active/passive coping) to reduce mortality. However, the most efficacious coping strategies, we conclude, are those matched to characteristics of the individual.
\end{abstract}




\section{Introduction}

Stress processes are inherently intertwined with aging, and there are some stressors that are more common with increases in age than others. Indeed, given the different life transitions generally associated with older adulthood (e.g., retirement, death of a spouse/partner, role loss (Bossé, Aldwin, Levenson, \& Workman-Daniels, 1991; Elwell \& Maltbie-Crannell, 1981); loss of muscle mass and strength (Baumgartner, Stauber, McHugh, Koehler, \& Garry, 1995); the onset of illness, physical impairments and disabilities, visual, auditory, and cognitive impairments (Thomas et al., 1983); loneliness and isolation (Hawkley \& Cacioppo, 2007)), stress-inducing experiences often increase considerably in later life. And, stress, when improperly regulated has been shown to increase mortality risk - particularly among older adults (e.g. Aldwin et al., 2011; Krause, 1998).

Given the various life transitions that individuals tend to experience in older adulthood, it is no surprise that a number of scholars have sought to understand how older adults cope with stressful life situations - especially within the context of their mental and physical health (e.g. Kraaij, Garnefski, \& Maes, 2002; Moos, Brennan, Schutte, \& Moos, 2006). Past research, for instance, has identified a plethora of coping strategies (for an overview and critique see Skinner, Edge, Altman, \& Sherwood, 2003), with many scholars agreeing that coping is a multidimensional construct (Pearlin \& Schooler, 1978; Skinner et al., 2003) which can either be religious (Koenig, Pargament, \& Nielsen, 1998; Krause, 1998; Pargament, 1997) or secular in nature (Hampson, Glasgow, \& Zeiss, 1996; Murberg, Furze, \& Bru, 2004).

Despite the different coping strategies that exist, to our knowledge, there has been only one study comparing the use of religious versus secular coping strategies among older adults (Dunn \& Horgas, 2004). That study focused mainly on reporting the frequency of using religious and secular coping strategies, and did not analyze subsequent health outcomes of choosing either strategy. Our study, therefore, attempts to extend these findings by examining whether and to what extent the choice of religious or secular coping in older adulthood results in decreased mortality risk. Furthermore, we explore whether the effects differ depending on the choice of either a social or individual coping approach. Given that the proper identification and regulation of coping in later life can help to inform interventions to improve older adults' responses to life stressors, this study represents an important area of scholarly inquiry.

The remainder of the article proceeds as follows: We first review the literature on coping strategies among older adults, organizing the literature into categories of religious and secular coping. Within both categories we identify various social and individual approaches that can be used in the coping process. We next present a conceptual framework to formalize our research question. Our methods are then outlined before turning to our findings. In our findings, we begin by presenting a replication of prior research and examining the benefits associated with different coping strategies (i.e., religious and secular). We then add to the literature by testing the differential effects of individual and social approaches to coping as both secular and religious strategies. Finally, we examine the effects coping choice with respect to respondents' characteristics. We conclude with a discussion of our findings. 


\section{Literature Review}

There are multiple coping strategies utilized in older adulthood that have been identified in the literature. We divide our review into two main types of strategies: religious and secular. We examine both types of coping strategies and also identify the social and individual level approaches available within each domain.

\section{Religious Coping Strategies}

For the purposes of this paper, we rely on Koenig and colleagues (1998) definition of religious coping strategies as "the use of religious beliefs or behaviors to facilitate problemsolving to prevent or alleviate the negative emotional consequences of stressful life circumstances" (p. 513). The use of religion as a coping strategy is hence distinct from the general concept of religiosity (such as frequency of prayer or church attendance) in that religious coping strategies are consciously chosen by individuals in their efforts to deal with stressful situations.

Among older adults, religious coping (e.g., seeking a connection with God, seeking support from congregation members, and giving religious help to others) has been shown to lead to improved self-perceived mental and physical health outcomes (Koenig et al., 1998). Religious coping has also been shown to lead to better objectively measured health outcomes in adult populations over the age of 18 (Wachholtz \& Pargament, 2005). In some instances, religious coping has even been found to buffer the negative effects of stressful events on mortality (Krause, 1998). Despite these potential beneficial effects, some studies have found that religious coping may not always have a positive outcome. Studies have shown, for instance, that spiritual discontent and reappraisal of God's powers might worsen, instead of benefit, mental and physical health — particularly among older adults (Koenig et al., 1998; Parenteau et al., 2011; Pargament, Smith, Koenig, \& Perez, 1998).

A number of different approaches to religious coping have been identified in the literature. These approaches include both individual and socially-focused coping practices (Stark \& Glock, 1968). Individual approaches to religious coping may include engaging in private prayer or reading religious book. These coping approaches are distinct ways of expressing personal faith, but do not necessitate social engagement with a religious community (Wuthnow, 1991). Social coping approaches rely on the integration of individuals into a broader community of support. These approaches may include engaging in social activities such as church attendance or joining bible study groups (Stark \& Glock, 1968).

Despite these distinctions, many studies tend to combine individual and social religious coping into a single measure of religious coping (Bjorck \& Thurman, 2007; Krause, 1998). For example, Krause (1998) combined both social and individual approaches to coping and investigated the effect of religious coping on different life roles. He found a positive effect of religious coping for less educated and older adults. Bjorck and Thurman (2007) examined the effects of religious coping strategies on psychological functioning, and similar to Krause (1998), combined social and individual approaches into one measure. They found that religious coping did buffer the effects of negative events on psychological functioning. In a study among AfricanAmerican HIV-positive women, a combined measure of religious coping was also shown to be negatively correlated with anxiety (Woods, Antoni, Ironson, \& Kling, 1999). 
Individual Approaches to Religious Coping. Other studies have looked only at individual approaches to religious coping, such as the use of prayer (Ai, Peterson, Bolling, \& Koenig, 2002; Wachholtz \& Sambamoorthi, 2011). For example, Ai et al. (2002) found that saying prayers was positively associated with optimism among a sample of middle-aged adults scheduled for cardiac surgery. Wachholtz and Sambamoorthi (2011) investigated the prevalence of using prayer as a coping approach, and found that not only has an increasing number of Americans begun turning to prayer as a coping mechanism, but those that relied on prayer were more likely to engage in health protective behaviors.

Social Approaches to Religious Coping. Although church attendance is frequently included as a general measure of religiosity, church attendance has rarely been included as a distinct approach to coping. Still, church attendance as a general measure of religiosity has consistently been shown to be associated with better physical health (e.g. fewer medical diagnoses, less overall severity of illness, better subjective health problems) as well as better mental health (e.g. less depression, greater quality of life) — particularly in older adults who experience both acute and chronic physical health problems (Koenig et al., 1998). Furthermore, frequent church attenders have also been found to have a reduced mortality risk, when controlling for mental and physical health (Strawbridge, Cohen, Shema, \& Kaplan, 1997). Some qualitative findings have provided insights into possible explanations as to why church attendance might serve as an effective approach to coping. Siegel \& Schrimshaw (2002), for instance, have found that participating in religious services ignites a sense of belonging among older adults living with HIV/AIDS, and buffers against feelings of isolation. Ultimately, church attendance was shown to affirm the self-worth of the individuals despite their illness.

\section{Secular Coping Strategies}

In addition to religious coping strategies, there are also a number of non-religious, or secular, coping strategies that exist. Within this domain, the scholarly literature focuses on two distinct approaches: First, active versus passive coping - both of which are generally individually-focused. Second, as a social approach to secular coping, a recent trend has been to focus on various forms of collective social engagement, such as volunteering.

Individual Approaches to Secular Coping: Active versus passive coping. Active and passive coping approaches are distinct independent constructs (Snow-Turek, Norris, \& Tan, 1996). Qualitative research has shown that among adults aged 65 and older, those who applied more active coping approaches were characterized as "striving to maintain independence and control [through] maneuvering between available resources" (Dunér and Nordström, 2005, p. 444). Individuals who utilized more passive coping approaches were described as having "given up control over their lives" (p. 446).

Past research has also focused on a variety of health outcomes related to both active and passive coping approaches among older adults. For instance, among older adults who suffered from acute and chronic physical health problems, active coping was positively related to mental health outcomes (Koenig et al., 1998). Similarly, in a study among older adults coping with osteoarthritis, active coping significantly predicted less depressive affect at follow up. In the same study, passive coping behaviors predicted an increase in individuals' negative affect. Those who perceived themselves as sicker were more prone to utilize passive coping approaches and had more depressive symptoms at follow up (Hampson et al., 1996). Some studies have investigated the relationship between active and passive coping and mortality risk. For instance, in a longitudinal study among veterans with end-stage renal disease, Wolf and Mori (2009) 
found that avoidant coping (which is considered a passive coping approach) was associated with increased mortality risk, whereas active coping strategies were not associated with increased mortality risk.

Social Approaches to Secular Coping. In recent years, a number of scholars have found that volunteering can positively impact health and mortality risk (see Okun, WanHeung Yeung, \& Brown, 2013 for a meta-analysis). For example, volunteering among older adults has been shown to be associated with a significant reduction in depressive symptoms (Banerjee, Perry, Tran, \& Arafat, 2010). Moreover, recent longitudinal findings indicate that well-being and volunteering can mutually influence one another. Indeed, Thoits \& Hewitt (2001) found that individuals who had better physical and mental health were not only more likely to engage in volunteer work, but were also more likely to have the necessary "internal coping resources that expedite[d] seeking out volunteer opportunities, becoming involved, staying involved" (p. 118). Volunteering has also been shown to be positively associated with increased personal well-being, independent of other religious or secular community participation. A recent meta-analysis, for instance, found that even when controlling for various social and demographic covariates, volunteers experienced a twenty-five percent reduction in mortality risk on average compared to non-volunteers (Okun et al., 2013).

Although the benefits of volunteering seem to be well-established, there is little research examining whether individuals consciously select volunteer work as a means to cope with life stressors. One recent exception is a study which examined the relationship between coping strategies and health outcomes among retirees in the UK (Lowis, Jewell, Jackson, \& Merchang, 2011). In this study, engaging in helping behaviors was included as a coping strategy (e.g., "helping others, which also helps me"). The findings indicated that giving to others as a way of coping was highly ranked among the retirees as a secular coping approach. Thus, as Jiranek, Brauchli, and Wehner (2014) have recently argued, volunteering may offer compensatory and beneficial effects that can positively impact how individuals view life's stressors and ultimately may facilitate relaxation and recovery thereby enabling individuals to better cope in other life domains.

\section{Conceptual Framework}

Given the evidence that both religious and secular coping strategies can be useful for dealing with life stressors. In the current study, we are particularly interested in investigating whether, and to what extent, different approaches to coping can be beneficial for specific populations. Person-environment fit theory suggests that the match between individuals' characteristics and their environment is important in determining well-being (Kristof-Brown \& Guay, 2011). Although this theory is generally applied to organizational settings, we conceptually extend the theory to individuals' psychological and physical environment. For example, a religious person may be more likely to benefit from the use of religious-based coping strategies than a non-religious person. Religious individuals may also differ in the approach to coping that they choose. Some, for instance, may draw on more internal psychological resources (such as prayer or reading religious literature). Others, however, may desire to physically place themself within a religious environment (e.g. attending religious services, bible studies, and other events) in order to cope with stressful situations. 
We also draw on the concept of "meaning" (Burke, 1991; Thoits, 1991) and build on Krause's (1998) concept of religious identity. An individual's self-described religious preference can represent a distinct social identity, and this identity may influence both the choice of, and the outcome(s) resulting from, coping behaviors (Lowis et al., 2011). Accordingly, the purpose of this study is to investigate differences in the effect of coping strategy on mortality risk for those who self-classify as religious and those who self-classify as non-religious. As shown in Figure 1, our conceptual model indicates that individuals may choose a coping strategy (religious or secular) and within that strategy they may rely on a specific approach (individual or social).

\section{Data}

\section{Data and Variables}

Data from the Wisconsin Longitudinal Study (WLS) was used in this study. The WLS follows a randomly selected sample of 10,317 men and women who graduated from Wisconsin high schools in 1957. The sample is broadly representative of predominantly Caucasian individuals. Thus, the sample has a low representation of ethnic minorities. For the purposes of this study, we focus specifically on respondents who answered questions of interest relating to use of coping strategies (reported below) in three waves of data from the WLS: 1992, 2004, and 2009 ( $n=3146)$. Respondents in our study were majority female $(54.6 \%)$, with a mean age of 70.12 in 2009 (range $=69$ to 72). Full details about the WLS, including the samples from each year, response rates, weightings, and interview formats can be found on the WLS website: http://www.ssc.wisc.edu/wlsresearch/pilot/.

\section{Variables}

Dependent Variable. Our dependent variable of interest is mortality status in 2009, which was determined using National Death Index records. The variable is coded as a dichotomous indicator of alive or deceased $(0=$ alive, $1=$ deceased $)$.

Independent Variable(s). We examined the effects of various coping strategies (as assessed in 2004) on mortality status, controlling for a number of potential confounders. Coping strategies were classified as either religious or secular, and coping approaches were included that represented both individual and social behaviors (see Figure 1).

In terms of religious coping strategies, the more social form of religious coping involved attending services. Specifically, in the WLS respondents were asked, When you have problems or difficulties in your family, work, or personal life, how often do you seek comfort through attending a religious or spiritual service? Response options included: 1=never, 2=rarely, $3=$ sometimes, $4=$ often. The more individual form of religious coping involved using prayer to cope. Respondents were also asked, When you have problems or difficulties in your family, work, or personal life, how often do you seek comfort through praying" Response options to this question included: $1=$ never, $2=$ rarely, $3=$ sometimes, $4=$ often. Respondents were also asked to report how religious they believed themselves to be-with response options ranging from $1=$ not at all religious, $5=$ extremely religious.

In terms of secular coping strategies, the more social form of secular coping involved two items in the WLS taken from the Volunteer Functions Inventory (Clary et al., 1998). These items assessed the extent to which respondents used volunteering as a way to: 1) help them work 
through their own personal problems, and 2) help them escape their own troubles. Response options included: $1=$ not at all important / accurate to 7=extremely important / accurate. The two items were combined to create a single measure of social secular coping $(\alpha=.79)$. Two individual forms of secular coping approaches were included in the WLS: active and passive coping. Active coping was assessed using eight items taken from the Brief Coping Inventory (Carver, 1997; e.g. Generally, when you experience a difficult or stressful event, how often do you take actions to try and make the situation better?; $1=\mathrm{I}$ usually do not do this at all, $2=\mathrm{I}$ usually do this a little bit, $3=$ I usually do this a medium amount, $4=$ I usually do this a lot; $\alpha=.82$ ). Passive coping was assessed using nine items from the same inventory and the same response options (e.g. Generally, when you experience a difficult or stressful event, how often do you give up the attempt to cope?; $\alpha=67$ ). See Appendix A for the full-scale items.

Control Variables. We included a number of covariates in the analysis to account for the possibility that any effects that we found resulted from underlying physical, social, or psychological factors. Controlling for these factors is important, since meta-analytic results have consistently shown that the relationship between religious involvement and mortality can be partly explained by other demographic, psychosocial, or health-related variables (McCullough, Hoyt, Larson, Koenig, \& Thoresen, 2000).

Demographic covariates. Very little variance exists in age in the current study. Still, we controlled for age, as well as gender $(1=$ male, $0=$ female $)$. Both women and older individuals are likely to be more religious than men and younger people, and both of these variables have been shown to be associated with mortality risk (McCullough, et al 2000). Other demographic covariates included the number of years of education respondents had, respondents' net worth, and their employment status in 2004 (1=working for pay, $0=$ not working at all).

Social covariates. It is possible that general differences in social connectedness or social tendencies might underlie the predicted differential effects of coping strategy on mortality risk. Because of this, we also controlled for a number of social variables. Marital status $(1=$ married, $0=$ not married, i.e. separated, divorced, widowed, or never married) was assessed in 2004. Respondents were also asked about the number of hours they volunteered per month in the past year, and the number of times they got together with friends (e.g. going out together, visiting each other's homes) in the past four weeks. Both of these variables were included as controls. In addition to these variables, we included a measure of extraversion as individuals with greater social connections have been shown to be in better mental and physical health (REFS). Extraversion was assessed by summing six items from the Big Five Inventory (version 4a and 5a: John, Donahue, \& Kentle, 1991; 1 = agree strongly, $6=$ disagree strongly; $\alpha=.75$ ).

Health covariates. Finally, we controlled for a number of physical, psychological, and cognitive health variables from 1992. Physical health was assessed using three variables. First, respondents reported the total number of physician diagnosed medical illnesses, based on a list of seventeen potential illnesses: anemia, asthma, arthritis/rheumatism, bronchitis/emphysema, cancer, chronic liver trouble, diabetes, serious back trouble, heart trouble, high blood pressure, circulation problems, kidney or bladder problems, ulcers, allergies, multiple sclerosis, colitis, or some other illness or condition. We also included self-rated evaluations of respondents' overall health in 2004 (1=poor, 2=fair, 3=good, 4=very good, 5=excellent), and reports of whether they ever had any long-term physical or mental conditions, illnesses or disabilities that limited what they were able to do, either on or off the job? $(1=\mathrm{yes}, 0=\mathrm{no})$. 
Health risk behaviors were assessed using reports of respondents' lifetime smoking history $(1=y e s$, is a regular smoker; $0=$ no), current drinking behavior $(1=y e s ; 0=$ no), and body mass index (BMI). Mental and cognitive health was assessed using four items. Depression history was assessed by responses to the following question: Have you ever had a time in life lasting two weeks or more when nearly every day you felt sad, blue, depressed, or when you lost interest in most things like work, hobbies, or things you usually liked to do for fun? (1=yes, $0=$ no). Respondents were also asked to report their lifetime prevalence of major stressful events (e.g. natural disaster, served in combat, witnessed severe injury or death, debt or financial loss, legal difficulties, incarceration, spousal abuse, child seriously ill or injured, etc.). Finally, cognitive health was only measured in 2004, and was assessed via respondents' short-term memory scores for a list of random words ( 0 to 10 words correct) and also through a cognitive letter fluency test in which they are asked to list as many words as possible that start with a specific letter.

\section{Results}

Part 1: Replicating Past Research. We first examined whether coping strategies depend on respondents' religiosity. To do so, we ran a series of ANOVAs examining the influence of religiosity (religious versus non-religious) on the different coping strategies. Not surprisingly, when compared to non-religious respondents, religious respondents were more likely to use religiously oriented coping strategies - social (i.e., attending religious services) and individual (i.e., prayer) approaches, $p s<.001$ (See Table 1). However, religious and non-religious respondents were equally as likely to use secular strategies that focused on individual approaches to coping-active approaches, $F(1,6538)=.18, p=.67$, and passive, $F(1,6536)=2.38, p=.12$. Finally, the findings indicate that despite the fact that volunteer opportunities may not necessarily be linked to a religious institution, religious respondents were more likely to report using volunteering as a means to cope than non-religious respondents, $p<.001$ (Table 1).

We next estimated a hierarchical binomial logistic regression model to examine the relationship between different coping strategies for dealing with problems and difficulties in 2004 and mortality risk five years later (2009), controlling for a number of potential variables. Step 1 included demographic variables as covariates, Step 2 included social embeddedness variables, and Step 3 included a number of different health-related covariates. In Step 4, we examined the main effects of each of the coping strategies (mean-centered) on later mortality risk. (See Table 2 for descriptive statistics and inter-correlations among the various coping strategies).

As can be seen from Table 3 (Step 4), respondents who reported being more religious in 2004 had a marginally lower risk of mortality five years later, $\beta=-0.25, p=.07$, Odds ratio $=$ $0.74,95 \%$ C.I.[.59, 1.03]. However, different religious behaviors predicted mortality in different ways. When focusing on the sample as a whole, more frequent church attendance was associated with reduced mortality risk, $\beta=-0.33, p=.006$, Odds ratio $=0.72,95 \%$ C.I.[.57, .91], while more frequent prayer was associated with increased mortality risk, $\beta=0.51, p<.001$, Odds ratio $=1.66,95 \%$ C.I. $[1.26,2.20]$. Moreover, active coping strategies were associated with marginally lower mortality risk, $\beta=-0.28, p=.10$, Odds ratio $=0.75,95 \%$ C.I.[.54, 1.06]. No other main effects emerged, $p s>.37$. 
Part 2: Matching the Health Benefits of Coping Strategies. We next examined the effect of interactions between religiosity and the various coping approaches by entering interaction terms into Step 5 of the model.

As can be seen from Table 4, the interactions between religiosity and church attendance, $\beta=-0.59, p=.05$, Odds ratio $=0.56,95 \%$ C.I. $[.31,1.00]$, religiosity and passive coping, $\beta=-$ $1.62, p=.005$, Odds ratio $=0.20,95 \%$ C.I.[.06, .62], and religiosity and volunteering are all significant, $\beta=0.40, p=.03$, Odds ratio $=1.50,95 \%$ C.I.[1.04, 2.15], while the interactions between religiosity and the other variables do not approach significance, $p s>.23$. In order to examine these interactions in more depth we split the data file by those who self-classified as religious $(n=2619)$ and those who did not $(n=527)$ and examined the effects of the various coping strategies within each group (Step 4), controlling for all previously mentioned covariates (Steps 1 to 3$)$.

Non-religious respondents. As can be seen from Table 4, for non-religious individuals there was no effect of religious coping strategies on later mortality risk, $p s>.38$. Although the effects were non-significant, they were in the direction that, if anything, religious behaviors were associated with higher mortality risk. Moreover, there was no effect of active coping approaches for non-religious individuals, $p>.80$. What really seemed to predict later mortality risk for nonreligious respondents was their use of passive coping styles, which predicted higher mortality risk five years later, $\beta=1.43, p=.02$, Odds ratio $=4.17,95 \%$ C.I.[1.23, 14.07], and their use of volunteering to cope, which predicted a lower later mortality risk, $\beta=-0.47, p=.03$, Odds ratio $=0.63,95 \%$ C.I. $[.41, .95]$.

Religious respondents. For religious individuals there was no effect of passive coping strategies on later mortality risk, $p>$.48. Instead, the strongest effects were seen for religious behaviors. Using prayer to cope predicted a higher mortality risk five years later, $\beta=0.45, p=$ .01, Odds ratio $=1.57,95 \%$ C.I. $[1.11,2.22]$, and using church attendance to cope was associated with a lower later mortality risk, $\beta=-0.46, p<.001$, Odds ratio $=0.63,95 \%$ C.I.[.50, .80]. In addition, religious individuals benefitted from more active coping strategies, $\beta=-0.39, p=.04$, Odds ratio $=0.67,95 \%$ C.I.[.47, .97]. Surprisingly, for those who were religious, volunteering actually had a marginally significant effect of increasing their mortality risk, $\beta=0.12, p=.08$, Odds ratio $=1.13,95 \%$ C.I.[.99, 1.29].

\section{Discussion and Conclusions}

In the overall sample of respondents, we replicated prior research on the benefits of religious coping strategies (Krause, 1998; Strawbridge et al., 1997). However, we also distinguished between individual and social approaches to coping and found that the use of religious coping strategies that were more individual in nature (such as prayer) actually increased mortality risk in older adults. To our knowledge, this is the first demonstration of such a finding. Prior research has focused primarily on health-related outcomes other than mortality risk. Moreover, prior studies have not examined distinctions between social and individual coping approaches within a single predictive model. Our results suggest that attending church to cope (controlling for the effects of the use of prayer as a coping strategy) is good for one's health, but praying to cope (controlling for the effects of attending church as a coping strategy) may be detrimental for one's health. Although both approaches seem to co-occur (see Table 1), when the independent effects of the approaches are teased apart, one approach seems to be more protective than the other. This may result from the social nature of attending religious services, although we cannot be sure of this without further evidence. In general though, research has consistently 
shown that social integration and support can buffer against many negative health outcomes (Thoits, 2011)

In terms of secular coping strategies, in the overall sample we found that the only strategy that affected mortality risk was the extent to which individuals used active coping approaches to deal with their problems and difficulties. This finding is in contrast to Wolf and Mori (2009), who found no effect of active coping on how individuals dealt with stress. It is not entirely clear as to why the other two secular strategies were not significant in the model.

Next, we examined the extent to which the match between individual differences and coping approaches mattered in terms of mortality risk. We found that the use of religious coping strategies by non-religious adults had no effect on mortality risk. It was only the use of secular coping strategies that seemed to affect the risk of mortality. Passive coping, an individual secular approach to coping, was associated with a higher mortality risk while volunteering, a social secular coping approach, was associated with a lower mortality risk. Among religious individuals, religious coping strategies had the most powerful effects on their mortality risk. Church attendance, a social religious coping approach, was associated with a lower mortality risk, while prayer, a more individual religious coping approach, was associated with a higher mortality risk.

We also found that there was an additional mortality risk reduction associated with active coping strategies among religious individuals. We speculate (but cannot prove) that this may be because they use other social religious approaches as part of their active coping (e.g. attending bible study groups, seeking prayer support from others, etc.). Interestingly, although volunteering was associated with a lower mortality risk among non-religious respondents, it was actually related to a higher risk of mortality among religious respondents. Taken together, these findings highlight the practical importance of recommending coping strategies that match individuals' characteristics and lifestyles.

\section{Conclusions: Strengths, Limitations, and Future Directions}

Our study has a number of strengths. First, we match individual differences to health consequences of coping strategies, something that previous studies have not done. As such, this conceptual framework can be applied when assessing other types of individual differences (e.g. education, ethnicity), coping strategies, and health outcomes. Moreover, this study highlights the importance of designing interventions to help older adults cope with life stressors that take into account the unique characteristics of the individual. Health communication studies find that individuals are more likely to respond to interventions, and be positively influenced by them, if the interventions match important demographic characteristics of the recipients (Kreuter, Strecher, \& Glassman, 1999). Thus, future researchers may want to examine whether it is beneficial for mental or physical health to train religious people to cope with problems using religious-based social coping approaches, and to train non-religious people to cope with problems using secular social coping approaches.

Despite these strengths, there are a number of limitations to this research. First, although we attempted to control for a number plausible confounders, it is possible that we missed important variables. Additionally, although the WLS asks respondents about their voluntary involvement, the study does not ask respondents about the activities that they volunteered withthus, it is unclear where respondents volunteered their time. Future research might investigate different types (religious versus non-religious) of volunteering to get a better sense of whether person-environment fit is important at this level. It is also unclear what tasks respondents 
performed while volunteering. Some volunteering tasks are done independently, while other tasks are more group-based. Research has shown that if direct social interaction is part of the volunteer experience, individuals will have better well-being compared to when their volunteer jobs do not involve direct social interactions (Wheeler, Gorey, \& Greenblatt, 1998). Finally, respondents in the WLS were predominantly Caucasian, with a low representation of ethnic minorities. Thus, generalizations of these findings to diverse racial/ethnic groups are cautioned.

Overall, we found that it is important for individuals to select coping strategies that match their level of religiosity, and within this general type of strategy (secular versus religious), social approaches to coping seem to be more beneficial to one's health than more individual approaches. Older adults face a number of challenges related to role and relationship loss as they age, and it is important to help to identify and recommend targeted coping strategies depending on their individual characteristics. 


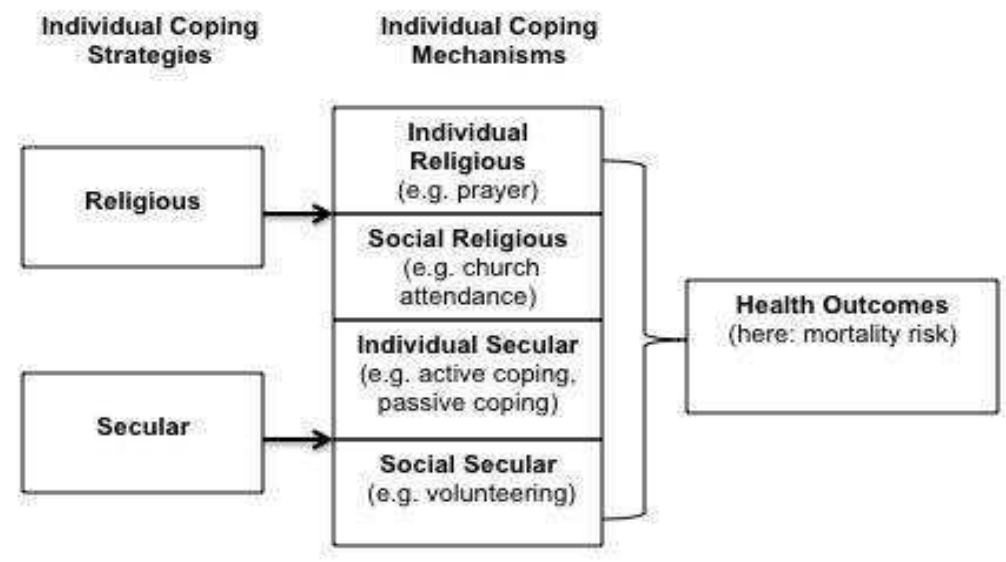

Figure 1: Conceptual Framework 
Table 1. Coping strategies depending on religiosity

\begin{tabular}{|l|c|c|l|}
\hline Coping Strategy & $\begin{array}{c}\text { Religious } \\
\text { individuals }\end{array}$ & $\begin{array}{c}\text { Non-religious } \\
\text { individuals }\end{array}$ & $\mathrm{F}, \mathrm{p}$ \\
\hline Attending religious services & 2.96 & 1.46 & $\mathrm{~F}(1,6583)=2393.26, \mathrm{p}<.001$ \\
\hline Prayer & 3.55 & 2.06 & $\mathrm{~F}(1,6597)=3607.02, \mathrm{p}<.001$ \\
\hline Active Coping & 3.03 & 3.02 & $\mathrm{~F}(1,6538)=.18, \mathrm{p}=.67$ \\
\hline Passive Coping & 1.79 & 1.77 & $\mathrm{~F}(1,6536)=2.38, \mathrm{p}=.12$ \\
\hline Volunteering & 2.51 & 2.01 & $\mathrm{~F}(1,6076)=92.78, \mathrm{p}<.001$ \\
\hline
\end{tabular}

Table 2. Coping strategies and their correlations

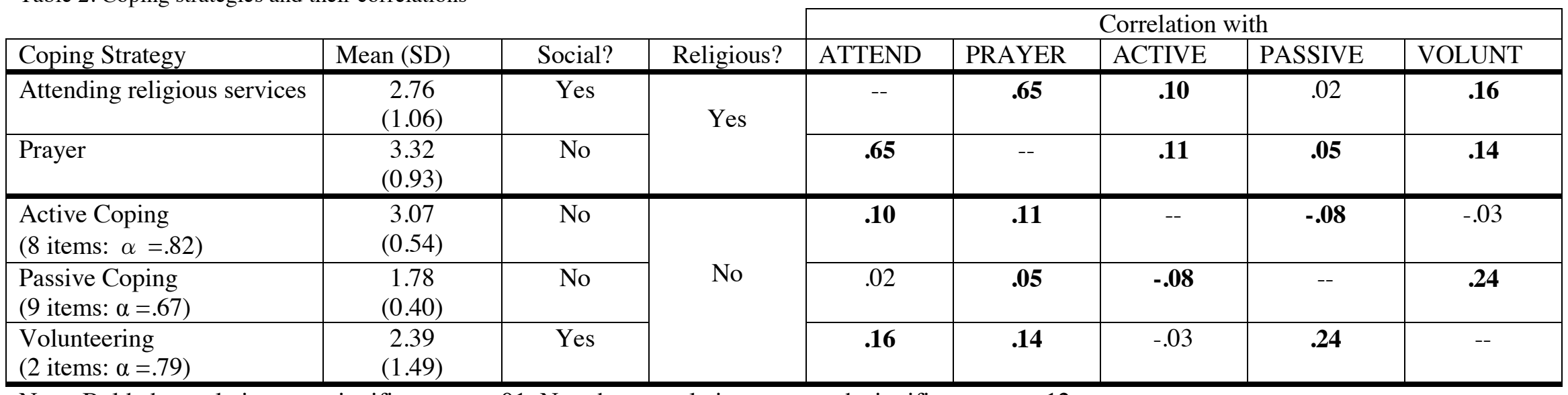

Note: Bolded correlations are significant at $\mathrm{p}<.01$. No other correlations approach significance, $\mathrm{ps}>.12$. 
Table 3. Hierarchical logistic regression model used to predict mortality risk from coping strategies (Part 1).

\begin{tabular}{|c|c|c|c|c|c|c|c|c|}
\hline & \multicolumn{2}{|l|}{ Step 1} & \multicolumn{2}{|l|}{ Step 2} & \multicolumn{2}{|l|}{ Step 3} & \multicolumn{2}{|l|}{ Step 4} \\
\hline & $\beta$ & $\begin{array}{l}\text { Odds } \\
\text { ratio }\end{array}$ & $\beta$ & $\begin{array}{l}\text { Odds } \\
\text { ratio }\end{array}$ & $\beta$ & $\begin{array}{l}\text { Odds } \\
\text { ratio }\end{array}$ & $\beta$ & $\begin{array}{l}\text { Odds } \\
\text { ratio }\end{array}$ \\
\hline \multicolumn{9}{|l|}{ Demographic variables } \\
\hline Age & 0.11 & 1.11 & 0.11 & 1.12 & 0.12 & 1.13 & 0.13 & 1.14 \\
\hline Gender & 0.27 & 1.31 & 0.27 & 1.31 & 0.06 & 1.06 & 0.14 & 1.15 \\
\hline Education & $-0.11 *$ & 0.90 & $-0.09 *$ & 0.92 & -0.06 & 0.94 & -0.05 & 0.95 \\
\hline Net worth & 0.00 & 1.00 & 0.00 & 1.00 & 0.00 & 1.00 & 0.00 & 1.00 \\
\hline Employment status & -0.19 & 0.83 & -0.24 & 0.78 & -0.16 & 0.85 & -0.16 & 0.86 \\
\hline \multicolumn{9}{|l|}{ Social embeddedness } \\
\hline Marital status & & & $-0.67 * *$ & 0.51 & $-0.64 * *$ & 0.53 & $-0.58 * *$ & 0.56 \\
\hline Hours volunteering & & & $-0.03 *$ & 0.97 & $-0.03 *$ & 0.97 & $-0.02 \sim$ & 0.98 \\
\hline Number of friend visits & & & -0.03 & 0.97 & -0.03 & 0.97 & -0.02 & 0.98 \\
\hline Extraversion & & & -0.01 & 0.99 & -0.01 & 0.99 & 0.00 & 1.00 \\
\hline \multicolumn{9}{|l|}{ Mental and physical health } \\
\hline Number of illnesses & & & & & -0.01 & 0.99 & -0.01 & 0.99 \\
\hline Self-rated health & & & & & $-0.25 \sim$ & 0.78 & -0.24 & 0.79 \\
\hline Functional status & & & & & 0.21 & 1.24 & 0.28 & 1.32 \\
\hline Smoking & & & & & $0.49 *$ & 1.64 & $0.42 *$ & 1.51 \\
\hline Drinking & & & & & 0.40 & 1.49 & 0.45 & 1.56 \\
\hline$B M I$ & & & & & $0.04 \sim$ & 1.04 & 0.04 & 1.04 \\
\hline Depression & & & & & -0.30 & 0.74 & $-0.43 \sim$ & 0.65 \\
\hline Stressful life events & & & & & 0.12 & 1.12 & 0.12 & 1.13 \\
\hline Short-term memory & & & & & -0.07 & 0.94 & -0.06 & 0.94 \\
\hline Cognitive fluency & & & & & 0.01 & 1.01 & 0.01 & 1.01 \\
\hline Religiosity & & & & & & & $-0.25 \sim$ & 0.78 \\
\hline \multicolumn{9}{|l|}{ Religious coping strategies } \\
\hline Church attendance & & & & & & & $-0.33 * *$ & 0.72 \\
\hline Prayer & & & & & & & $0.51 * *$ & 1.66 \\
\hline \multicolumn{9}{|l|}{ Secular coping strategies } \\
\hline Active coping & & & & & & & $-0.28 \sim$ & 0.75 \\
\hline Passive coping & & & & & & & 0.09 & 1.09 \\
\hline Volunteering to cope & & & & & & & 0.06 & 1.06 \\
\hline
\end{tabular}

Note: $\mathrm{N}=3146 . \sim \mathrm{p}<.10,{ }^{*} \mathrm{p}<.05, * * \mathrm{p}<.01$ 
Table 4. Predicting mortality risk from interaction between religiosity and coping strategies (Part 2).

\begin{tabular}{|c|c|c|c|c|c|c|}
\hline \multirow[b]{2}{*}{ Coping strategy } & \multicolumn{2}{|c|}{$\begin{array}{l}\text { Interaction with } \\
\text { Religiosity } \\
\text { (all participants) }\end{array}$} & \multicolumn{2}{|c|}{$\begin{array}{l}\text { Not Religious } \\
(\mathrm{N}=527)\end{array}$} & \multicolumn{2}{|c|}{$\begin{array}{l}\text { Religious } \\
(\mathrm{N}=2619)\end{array}$} \\
\hline & $\beta$ & $\begin{array}{l}\text { Odds } \\
\text { ratio }\end{array}$ & $\beta$ & $\begin{array}{l}\text { Odds } \\
\text { ratio }\end{array}$ & $\beta$ & $\begin{array}{l}\text { Odds } \\
\text { ratio }\end{array}$ \\
\hline \multicolumn{7}{|l|}{ Religious } \\
\hline Church Attendance & $-0.59 *$ & 0.56 & 0.12 & 1.13 & $-0.46 * *$ & 0.63 \\
\hline Praying & 0.21 & 1.23 & 0.26 & 1.29 & $0.45 * *$ & 1.57 \\
\hline \multicolumn{7}{|l|}{ Secular } \\
\hline Active Coping & -0.52 & 0.59 & 0.11 & 1.11 & $-0.39 *$ & 0.67 \\
\hline Passive Coping & $-1.62 * *$ & 0.20 & $1.43^{*}$ & 4.17 & -0.18 & 0.84 \\
\hline Volunteering & $0.40^{*}$ & 1.50 & $-0.47 *$ & 0.63 & $0.12 \sim$ & 1.13 \\
\hline
\end{tabular}

Note: $\sim \mathrm{p}<.10,{ }^{*} \mathrm{p}<.05, * * \mathrm{p}<.01$ 
Appendix A: Full text of coping strategy items

\begin{tabular}{|c|c|}
\hline Coping strategy & $\operatorname{Item}(\mathrm{s})$ \\
\hline \multicolumn{2}{|l|}{ Religious } \\
\hline Attending religious services & $\begin{array}{l}\text { When you have problems or difficulties in your family, work, or personal } \\
\text { life, how often do you seek comfort through attending a religious or } \\
\text { spiritual service? }\end{array}$ \\
\hline Prayer & $\begin{array}{l}\text { When you have problems or difficulties in your family, work, or personal } \\
\text { life, how often do you seek comfort through praying? }\end{array}$ \\
\hline \multicolumn{2}{|r|}{ 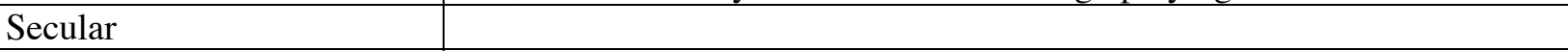 } \\
\hline Active Coping & $\begin{array}{l}\text { Generally, when you experience a difficult or stressful event... } \\
\text {...how often do you concentrate your efforts on doing something about the } \\
\text { situation you're in? } \\
\text {...how often do you take actions to try and make the situation better? } \\
\text {...how often do you try to see it in a different light or to make it seem more } \\
\text { positive? } \\
\text {...how often do you try to come up with a strategy about what to do? } \\
\text {...how often do you look for something good in what is happening? } \\
\text {...how often do you accept the reality of the fact that it has happened? } \\
\text {...how often do you learn to live with it? } \\
\text {...how often do you think hard about what steps to take? }\end{array}$ \\
\hline Passive Coping & $\begin{array}{l}\text { Generally, when you experience a difficult or stressful event... } \\
\text {...how often do you say to yourself 'this isn't real'? } \\
\text {...how often do you give up trying to deal with it? } \\
\text {...how often do you refuse to believe that it has happened? } \\
\text {...how often do you say things to let your unpleasant feelings escape? } \\
\text {...how often do you criticize yourself? } \\
\text {...how often do you give up the attempt to cope? } \\
\text {...how often do you do something to think about it less, such as going to } \\
\text { the movies, watching TV, reading, daydreaming, sleeping or shopping? } \\
\text {...how often do you express your negative feelings? } \\
\text {...how often do you blame yourself for things that happened? }\end{array}$ \\
\hline Volunteering & $\begin{array}{l}\text { How important or accurate, for you, is the following reason for why people } \\
\text { engage in volunteer activities... } \\
\text {...Volunteering helps me work through my own personal problems? } \\
\ldots \text { Volunteering is a good escape from my own troubles? }\end{array}$ \\
\hline
\end{tabular}




\section{References}

Ai, A. L., Peterson, C., Bolling, S. F., \& Koenig, H. (2002). Private prayer and optimism in middle-aged and older patients awaiting cardiac surgery. The Gerontologist, 42(1), 70-81.

Aldwin, C. M., Molitor, N.-T., Spiro, A., Levenson, M. R., Molitor, J., \& Igarashi, H. (2011). Do Stress Trajectories Predict Mortality in Older Men? Longitudinal Findings from the VA Normative Aging Study. Journal of Aging Research, 2011.

Banerjee, D., Perry, M., Tran, D., \& Arafat, R. (2010). Self-reported health, functional status and chronic disease in community dwelling older adults: untangling the role of demographics. Journal of Community Health, 35(2), 135-141.

Baumgartner, R. N., Stauber, P. M., McHugh, D., Koehler, K. M., \& Garry, P. J. (1995). Cross-sectional age differences in body composition in persons 60+ years of age. The Journals of Gerontology Series A: Biological Sciences and Medical Sciences, 50(6), M307-M316.

Bjorck, J. P., \& Thurman, J. W. (2007). Negative Life Events, Patterns of Positive and Negative Religious Coping, and Psychological Functioning. Journal for the Scientific Study of Religion, 46(2), 159167.

Bossé, R., Aldwin, C. M., Levenson, M. R., \& Workman-Daniels, K. (1991). How Stressful Is Retirement? Findings From the Normative Aging Study. Journal of gerontology, 46(1), P9-P14. doi: 10.1093/geronj/46.1.P9

Burke, P. J. (1991). Identity processes and social stress. American Sociological Review, 836-849.

Carver, C. S. (1997). You want to measure coping but your protocol's too long: Consider the Brief COPE. International Journal of Behavioral Medicine, 4, 92-100.

Clary, E. G., Snyder, M., Ridge, R. D., Copeland, J., Stukas, A. A., Haugen, J., \& Meine, P. (1998). Understanding and assessing the motivations of volunteers: A functional approach. Journal of Personality and Social Psychology, 74, 1516-1530.

Dunér, A., \& Nordström, M. (2005). Intentions and strategies among elderly people: Coping in everyday life. Journal of Aging Studies, 19(4), 437-451.

Dunn, K. S., \& Horgas, A. L. (2004). Religious and nonreligious coping in older adults experiencing chronic pain. Pain Management Nursing, 5(1), 19-28.

Elwell, F., \& Maltbie-Crannell, A. D. (1981). The impact of role loss upon coping resources and life satisfaction of the elderly. Journal of Gerontology, 36(2), 223-232.

Hampson, S. E., Glasgow, R. E., \& Zeiss, A. M. (1996). Coping with osteoarthritis by older adults. Arthritis \& Rheumatism, 9(2), 133-141.

Hawkley, L. C., \& Cacioppo, J. T. (2007). Aging and Loneliness Downhill Quickly? Current Directions in Psychological Science, 16(4), 187-191. 
Jiranek, P., Brauchli, R., \& Wehner, T. (2014). Beyond Paid Work: Voluntary Work and its Salutogenic Implications for Society Bridging Occupational, Organizational and Public Health (pp. 209229): Springer.

John, O. P., Donahue, E. M., \& Kentle, R. L. (1991). The big five inventory-versions 4a and 54. Berkeley: University of California, Berkeley, Institute of Personality and Social Research.

Koenig, H. G., Pargament, K. I., \& Nielsen, J. (1998). Religious coping and health status in medically ill hospitalized older adults. The Journal of Nervous and Mental Disease, 186(9), 513-521.

Kraaij, V., Garnefski, N., \& Maes, S. (2002). The joint effects of stress, coping, and coping resources on depressive symptoms in the elderly. Anxiety, Stress \& Coping, 15(2), 163-177.

Krause, N. (1998). Stressors in highly valued roles, religious coping, and mortality. Psychology and Aging, 13(2), 242.

Kreuter, M. W., Strecher, V. J., \& Glassman, B. (1999). One size does not fit all: the case for tailoring print materials. Annals of Behavioral Medicine, 21(4), 276-283.

Kristof-Brown, A., \& Guay, R. P. (2011). Person-environment fit.

Lazarus, R. S., \& Folkman, S. (1984). Stress, appraisal, and coping: Springer Publishing Company.

Lowis, M. J., Jewell, A. J., Jackson, M. I., \& Merchang, R. (2011). Religious and Secular Coping Methods Used by Older Adults: An Empirical Investigation. Journal of Religion, Spirituality \& Aging, 23, 279-303.

McCullough, M. E., Hoyt, W. T., Larson, D. B., Koenig, H. G., \& Thoresen, C. (2000). Religious involvement and mortality: a meta-analytic review. Health Psychology, 19(3), 211.

Moos, R. H., Brennan, P. L., Schutte, K. K., \& Moos, B. S. (2006). Older adults' coping with negative life events: common processes of managing health, interpersonal, and financial/work stressors. The International Journal of Aging and Human Development, 62(1), 39-59.

Murberg, T. A., Furze, G., \& Bru, E. (2004). Avoidance coping styles predict mortality among patients with congestive heart failure: a 6-year follow-up study. Personality and Individual Differences, $36(4), 757-766$.

Okun, M. A., WanHeung Yeung, E., \& Brown, S. (2013). Volunteering by Older Adults and Risk of Mortality: A Meta-Analysis.

Parenteau, S. C., Hamilton, N. A., Wu, W., Latinis, K., Waxenberg, L. B., \& Brinkmeyer, M. Y. (2011). The Mediating Role of Secular Coping Strategies in the Relationship Between Religious Appraisals and Adjustment to Chronic Pain: The Middle Road to Damascus. Social Indicators Research, 104(3), 407-425.

Pargament, K. I. (1997). The psychology of religion and coping: Theory, practice, research. New York: Guilford.

Pargament, K. I., Smith, B. W., Koenig, H. G., \& Perez, L. (1998). Patterns of Positive and Negative Coping with Major Life Stressors. Journal for the Scientific Study or Religion, 37(4), 710-724. 
Pearlin, L. I., \& Schooler, C. (1978). The structure of coping. Journal of Health and Social Behavior, 221.

Schoenmakers, E. C., van Tilburg, T. G., \& Fokkema, T. (2012). Coping with loneliness: What do older adults suggest? Aging \& Mental Health, 16(3), 353-360.

Siegel, K., \& Schrimshaw, E. W. (2002). The perceived benefits of religious and spiritual coping among older adults living with HIV/AIDS. Journal for the Scientific Study of Religion, 41(1), 91-102.

Skinner, E. A., Edge, K., Altman, J., \& Sherwood, H. (2003). Searching for the structure of coping: a review and critique of category systems for classifying ways of coping. Psychological Bulletin, $129(2), 216$.

Snow-Turek, A. L., Norris, M. P., \& Tan, G. (1996). Active and passive coping strategies in chronic pain patients. Pain, 64(3), 455-462.

Stark, R., \& Glock, C. Y. (1968). Patterns of Religious Commitment; I American Piety: The nature of Religious Commitment. Los Angeles, Berkeley: University of California Press.

Strawbridge, W. J., Cohen, R. D., Shema, S. J., \& Kaplan, G. A. (1997). Frequent Attendance at Religious Service and Mortality over 28 years. American Journal of Public Health, 87(6), 957961.

Thoits, P. A. (1991). On merging identity theory and stress research. Social Psychology Quarterly, 101112.

Thoits, P. A., \& Hewitt, L. N. (2001). Volunteer work and well-being. Journal of Health and Social Behavior, 115-131.

Thoits, P. A. (2011). Mechanisms linking social ties and support to physical and mental health. Journal of Health and Social Behavior, 52(2), 145-161.

Thomas, P. D., Hunt, W. C., Garry, P. J., Hood, R. B., Goodwin, J. M., \& Goodwin, J. S. (1983). Hearing acuity in a healthy elderly population: Effects on emotional, cognitive, and social status. Journal of Gerontology, 38(3), 321-325.

Van Willigen, M. (2000). Differential benefits of volunteering across the life course. The Journals of Gerontology Series B: Psychological Sciences and Social Sciences, 55(5), S308-S318.

Wachholtz, A., \& Pargament, K. I. (2005). A comparison of relaxation, spiritual meditation, and secular meditation and cardiac reactivity to a cold pressor task. Journal of Behavioral Medicine, 28, 369384.

Wachholtz, A., \& Sambamoorthi, U. (2011). National trends in prayer use as a coping mechanism for health concerns: Changes from 2002 to 2007. Psychology of Religion and Spirituality, 3(2), 67.

Wheeler, J. A., Gorey, K. M., \& Greenblatt, B. (1998). The beneficial effects of volunteering for older volunteers and the people they serve: a meta-analysis. International journal of aging \& human development, 47(1), 69-79. 
Wolf, E. J., \& Mori, D. L. (2009). Avoidant coping as a predictor of mortality in veterans with end-stage renal disease. Health Psychology, 28(3), 330.

Woods, T. E., Antoni, M. H., Ironson, G. H., \& Kling, D. W. (1999). Religiosity is associated with affective status in symptomatic HIV-infected African-American women. Journal of Health Psychology, 4(3), 317-326.

Wuthnow, R. (1991). Acts of compassion. Princeton: Princeton University Press. 